\title{
THE EFFECT OF IGNEOUS INTRUSIONS ON THE ACCUMULATION OF OIL IN NORTH- EASTERN MEXICO
}

V. R. GARFIAS

Los Angeles, Cal.

The region where the occurrences herein noted were observed comprises the portion of the Mexican coastal plain between the Panuco and Tuxpan rivers in the northern part of the state of Vera Cruz.

The formations involved in the geology of this area are of Cretaceous and Tertiary age, with unimportant Quaternary deposits near the coast. For convenience, they will be separated according to lithology into three divisions; the lower of which is made up of several thousand feet of limestones overlain by a series of alternating limestones and shales, the whole of Cretaceous age; the middle, of uniform shales and marls with a total thickness of about 3,000 feet, of upper Cretaceous-Eocene age; and the upper, of Tertiary sands, clays, limestones, and conglomerates, having an aggregate thickness of about 700 feet.

The marked characteristic of the geology of this region is the large number and magnitude of the volcanic intrusions, the remnants of which are represented in places by isolated basaltic cones, breaking the monotony of the coastal plain. The volcanic activity is more pronounced in the southern portion of the area, attaining its greatest development in the Otontepec range, an irregular basaltic mass about 2,000 feet high. The location of many of the intrusions was probably controlled by well-defined fault lines, and cross-faulting or any decided weakness of the underlying basement may also have played an important part in their distribution. The intrusions occurred during late Tertiary or possibly early Quaternary times, and consist of basalt accompanied in places by volcanic ash and conglomerate. Most of the surface indications of oil are closely associated with the basalts and hundreds of such 
phenomena occur throughout the area examined. Among the localities where oil seepages are abundant might be mentioned La Pez, La Dicha, Chijol, and Santa Margarita, near the Eban field; San Geronimo, La Merced, Rancho Abajo, Monte Alto, and Los Higueros, between the famous Dos Bocas and Casiano; Casiano, Cervantes, Tres Hermanos, Tinaja, Ojo de Brea, Chapopotillo, Monte Grande, Moralillo, Cerro Azul, Juan Felipe, Las Borrachas, Piedra Labrada, and Cerro Viejo, between the producing fields of Casiano and Potrero del Llano.

The intimate association of the volcanic intrusions and some of the producing fields is so apparent as to be unquestionable, and the problems in this connection relate chiefly to the effect of the basalt on the structure and texture of the intruded beds which resulted in their becoming capable of storing large amounts of oil under tremendous gas pressure.

The general conception of the form of these intrusions is that of a more or less irregular cone, in a normal position, the vertex of which may or may not reach the surface. Were these conditions fulfilled in the Mexican coastal plain, a well drilled near an outcrop of basalt would eventually strike the side of the cone and thus preclude further progress. This assumption is certainly not corroborated by actual experience in the fields, as many of the best producers are located in very close proximity to intrusions, and in some cases the basalt has been penetrated for several feet and the well continued to the oil reservoirs below.

In order to account for these discrepancies the writer performed a rather crude experiment, as a result of which were obtained some interesting data which seem to throw considerable light on the behavior of the intrusions and their effect on the intruded beds. Assuming the thickness of the uniform Cretaceous-Eocene shales as 3,000 feet, and that of the average intrusion as 1,000 feet, it was thought that the effect of the latter as it penetrated through the uniform series of shales would in some ways be parallel to that of a nail driven through an unbound book of a thickness three times as great as the diameter of the nail. The experiment was tried while the book was resting, first on a board, then on a folded blanket, and again on the open end of an inch pipe, and the 
results obtained were remarkably uniform. It was found that the leaves first penetrated were distorted only within a comparatively small radius, and that the zone of distortion increased toward the bottom in a more or less uniform ratio. A horizontal plan showed that in order to take care of the buckling near the nail, the first leaves had been torn at right angles and that the number of fissures naturally decreased as the zone of bending increased. It was also noticed that the fracturing and folding of any leaf around and near the nail was to a great extent controlled by the location and nature of displacement in the leaves immediately under, and this resulted in the formation of zones of dislocation along approximately vertical planes, most of which were closed before reaching the surface owing to the lesser number of fractures in the leaves last penetrated.

From these experimental observations and the results of actual experience in the developed portions of the fields, the following tentative conclusions have been drawn:

The thickness of the basalt intrusions as they pass through the Cretaceous-Eocene shales toward the surface increases roughly in a uniform ratio.

The horizontal zone of folding of the shales around the intrusions increases toward the surface.

The horizontal zone of fracturing varies with that of folding, but the number of fractures is greater in the deeper beds.

The fractures seem to occur along roughly vertical planes, thus forming deep well-like channels.

These vertical holes, partially filled with basalt and shale, could be effectively capped before reaching the surface, owing to the fewer number of fractures in the higher beds and the increasing cross-section of the intrusion toward the surface.

Before discussing the relation of the intrusions to the accumulation of the oil and gas, it is thought advisable to summarize certain views regarding the origin of the oil in this region:

For obvious reasons, the oil did not originate in the 700 feet of sandy limestones, conglomerates, and clays of Tertiary age, the remains of which are now exposed in patches here and there.

If the 3,000 feet of Cretaceous-Eocene shales were the source of the oil, they would show a more or less bituminous character 
throughout, or at least be of such an organic nature as to account for their furnishing the great quantities of oil in these fields. The shales which are exposed over nearly the whole area, however,

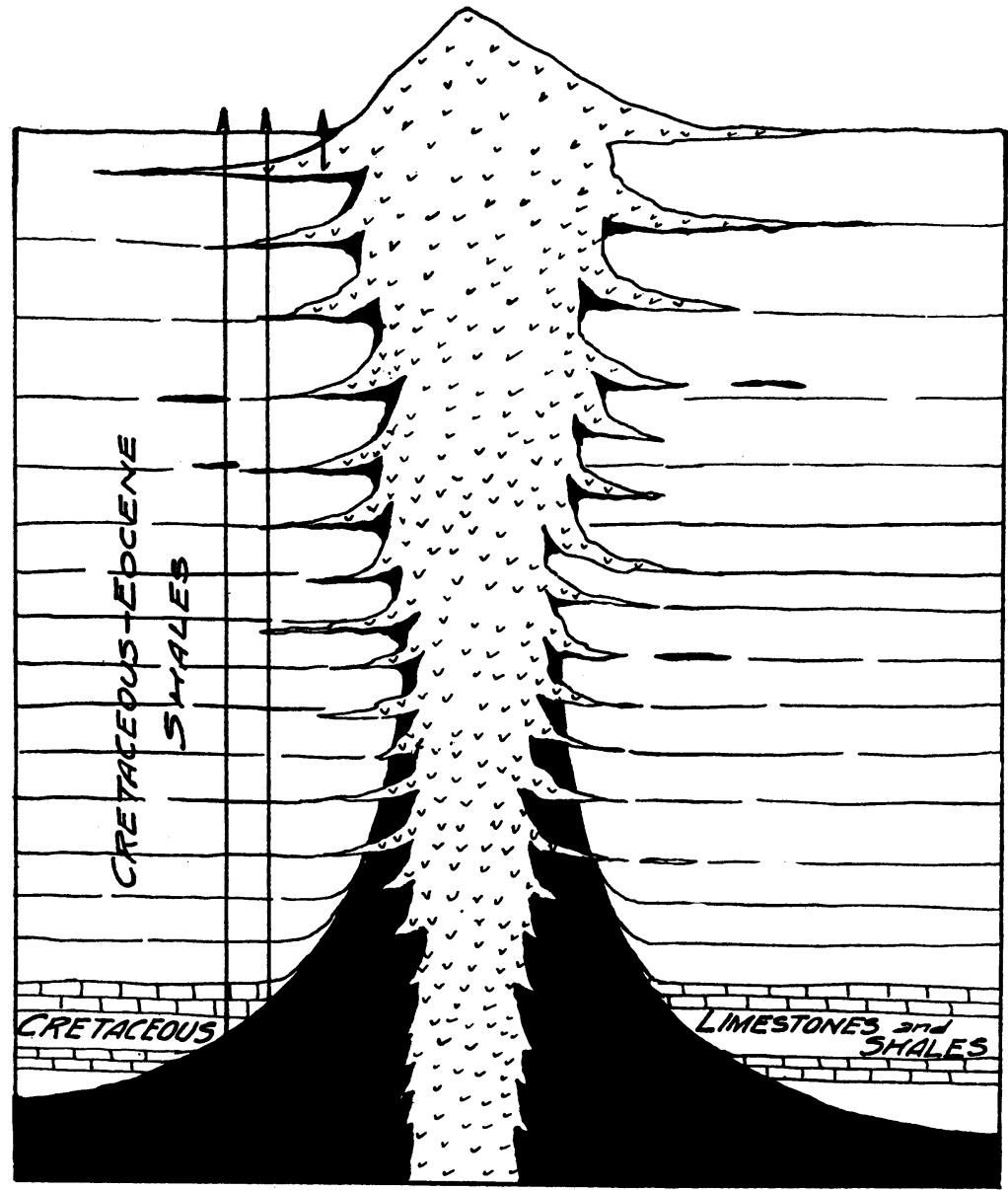

Fig. 1.-Hypothetical section showing basalt intrusion reaching the surface and resultant conditions in the intruded beds, conducive to the accumulation of oil. The two deep wells tapped the oil zone after penetrating the basalt, while the well nearest to the cone was abandoned in the basalt.

show signs of oil only near intrusions, and in all the exposures examined were of a uniform inorganic nature.

The migration of oil in impervious shales of this nature takes 
place mainly along bedding planes, and any barrier, such as the basalt intrusions, cutting across the planes of migration, will effectively intercept the flow. If resultant conditions are favorable, the vicinity of the barrier will become an ideal zone of concentra-

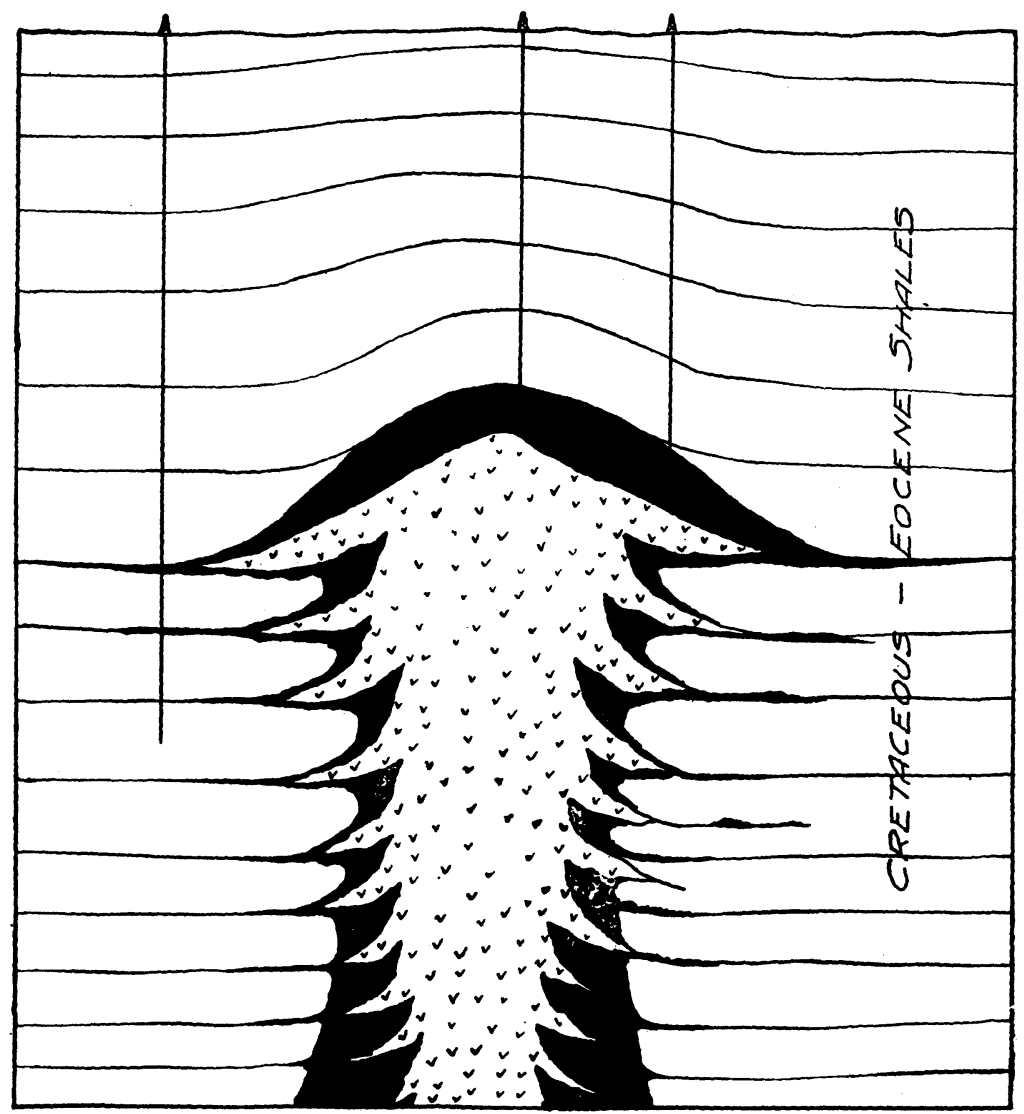

Fic. 2.- Hypothetical section of a basalt intrusion penetrating the CretaceousEocene shales to a point below the surface, illustrating how a deep well might encounter only "showings" of oil, and two neighboring shallower wells obtain a fair production in the shales.

tion for the flow of all the lateral channels penetrated, and, owing to the large drainage area contributing to the accumulation, this will be comparatively large, even if the amount of organic matter in the shales is small. In other words, the basalts which intrude 
the Cretaceous-Eocene shales certainly afford one of the most effective means to concentrate whatever hydrocarbons might have been disseminated throughout these beds.

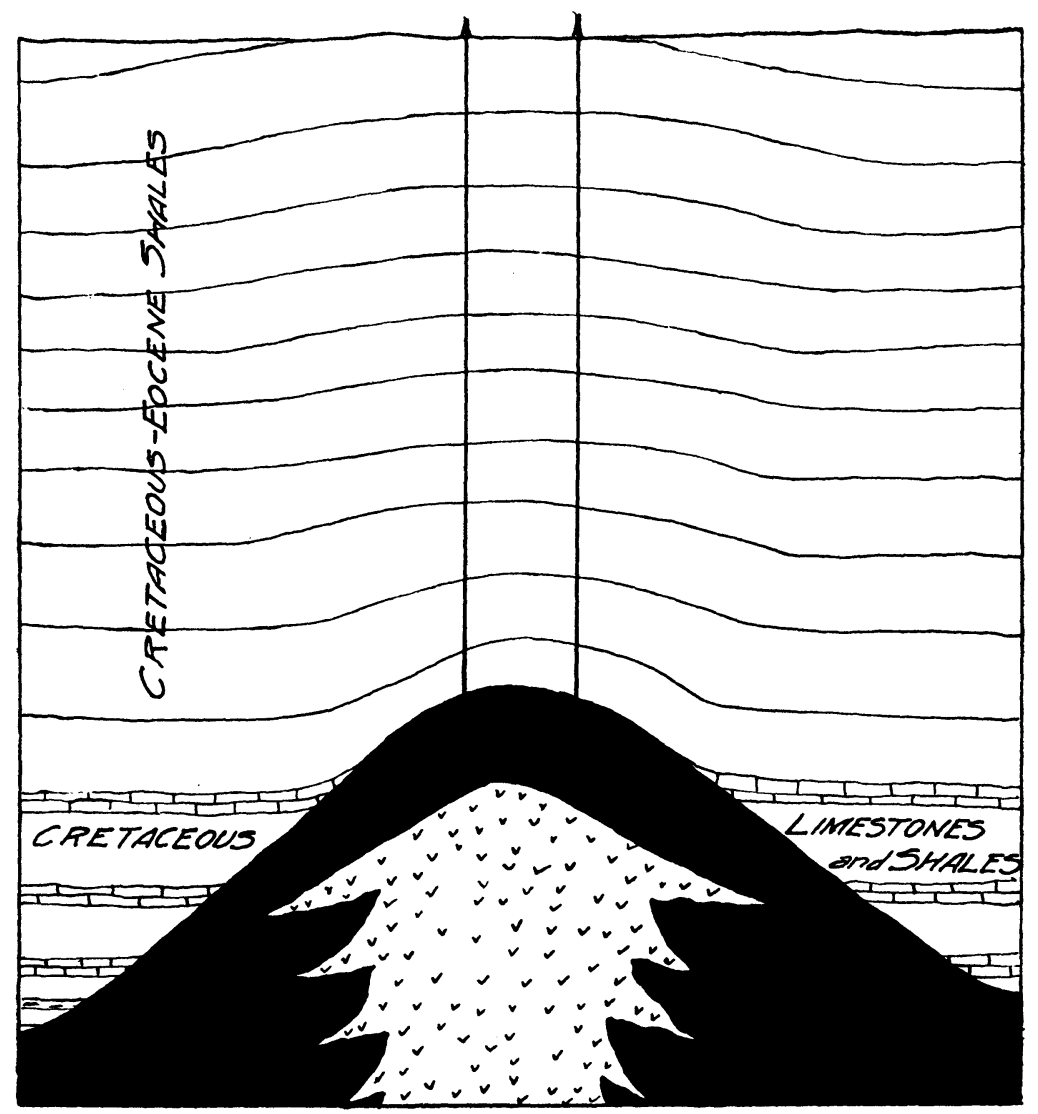

Fig. 3.-Hypothetical section of basalt intrusion penetrating the series of Cretaceous limestones and shales without disturbing the Cretaceous-Eocene shales, and giving rise to a dome of fractured and porous material, effectively covered with an impervious cap-rock. The large production of some of the Mexican gushers can readily be accounted for on this hypothesis.

Finally, it is apparent that if the Cretaceous limestones yielded the oil, it must have been before the event which changed them to their present compact and rather crystalline nature, and it is probable that such a condensation of the oil was coincident with 
the change in the nature of the beds. The oil could then have migrated along fissures toward the upper beds, aided by the action of water, and collected in the upper Cretaceous limestones and shales, to be concentrated in the favorable zones created by the igneous intrusions. Such migration had necessarily to take place after the deposition of the Cretaceous-Eocene cap-rock.

The accompanying figures summarize graphically the writer's conception of the effects of the igneous intrusions on the accumulation of oil in northeastern Mexico. Fig. I shows an intrusion which reaches the surface. In this case some oil may percolate through the shales, forming seepages near the basalt outcrop, and wells of varying productiveness may be located at comparatively short distances from the outcrop. If the intrusions penetrated the Cretaceous-Eocene shales to a point below the surface (Fig. 2), these would be arched above the basalt, thus affording a domeshaped reservoir in the shales, which might prove commercially productive for a comparatively short time. If, however, the intrusions perforated only a portion of the series of limestones and shales at the top of the Cretaceous limestones (Fig. 3), the resultant dome of porous and fractured material, capped by a thick cover of impervious shales, would form an ideal reservoir, which, if tapped, would readily account for the tremendous gushers characteristic of this region. Any and all of these conditions may exist, and it is probable that, with certain modifications, all do occur at one point or another in the portion of the Mexican coastal plain herein mentioned.

August 5 , I9I 2 